\title{
A randomised, placebo-controlled, double-blind study of aprepitant in nondrinking women younger than 70 years receiving moderately emetogenic chemotherapy
}

\author{
M Tanioka*, 1,2 , A Kitao ${ }^{1}$, K Matsumoto ${ }^{1}$, N Shibata ${ }^{3}$, S Yamaguchi ${ }^{4}$, K Fujiwara ${ }^{4}, \mathrm{H} \mathrm{Minami}^{2}$, N Katakami ${ }^{5}$, \\ S Morita ${ }^{6}$ and S Negoro ${ }^{1}$ \\ ${ }^{1}$ Medical Oncology, Hyogo Cancer Center, Akashi, Japan; ${ }^{2}$ Medical Oncology/Hematology, Kobe University Graduate School of \\ Medicine, Kobe, Japan; ${ }^{3}$ Department of Pharmacy, Hyogo Cancer Center, Akashi, Japan; ${ }^{4}$ Gynecologic Oncology, Hyogo Cancer \\ Center, Akashi, Japan; ${ }^{5}$ Division of Pulmonary Medicine, Kobe City Medical Center General Hospital, Kobe, Japan and ${ }^{6}$ Clinical \\ Research Coordinating Center, Yokohama City University Medical Center, Yokohama, Japan
}

Background: We evaluated the efficacy of aprepitant plus granisetron and an increased dose of dexamethasone in selected patients undergoing moderately emetogenic chemotherapy (MEC).

Methods: Nondrinking women $<70$ years undergoing MEC were randomly assigned to aprepitant (day 1, 125 mg; days 2 and 3, $80 \mathrm{mg}$ ) or placebo. Dexamethasone on days $1-3$ was 12,4 , and $4 \mathrm{mg}$ with aprepitant and 20, 8, and $8 \mathrm{mg}$ with placebo. The primary end point was complete response (CR; no emesis or rescue therapy) during $120 \mathrm{~h}$ of the first cycle. Logistic regression analysis was performed to identify predictors of overall CR.

Results: Of the 94 patients enrolled, 91 were assessable. Most received carboplatin-based chemotherapy. In the aprepitant $(n=45)$ and placebo $(n=46)$ groups, the overall, acute (day 1$)$, and delayed (days $2-5)$ CR rates were $62 \%$ and $52 \%, 98 \%$ and $96 \%$, and $62 \%$ and $52 \%$, respectively. Although not statistically significant, the overall CR rate was $10 \%$ higher in the aprepitant group. Both regimens were well tolerated. On multivariate analysis, advanced ovarian cancer (OR, $0.26(0.10-0.72))$ was independently associated with a lower CR.

Conclusion: Even with an increased dose of dexamethasone, aprepitant seemed more effective than placebo in these selected patients undergoing MEC; however, delayed phase management remains a significant problem.

Despite considerable progress in prevention, chemotherapy-induced nausea and vomiting (CINV) remain the most feared adverse effects among patients with cancer. Uncontrolled CINV can limit the dose intensity of chemotherapy and seriously compromise a patient's quality of life (Oo and Hesketh, 2005). The incidence of CINV depends primarily on the dose and type of chemotherapeutic agents administered. Published guidelines consistently classify carboplatin, irinotecan, and oxaliplatin as moderately emetogenic chemotherapy (MEC; Kris et al, 2006; Roila and Fatigoni, 2006). The risk of CINV also depends on gender and age; female and younger patients are at 
greater risk. In contrast, patients with a history of heavy alcohol consumption have a lower risk of CINV (Pollera and Giannarelli, 1989; Osoba et al, 1997; Schwartzberg, 2007; Hesketh, 2008; Hesketh et al, 2010).

For MEC regimens not based on anthracycline/cyclophosphamide (AC), recent guidelines, such as the National Comprehensive Cancer Network (NCCN) Antiemesis Guidelines version 1.2012 (Ettinger et al, 2012) and the American Society of Clinical Oncology (ASCO) guidelines for antiemetics (Basch et al, 2012), generally recommend the use of a 5-hydroxytryptamine 3 (5-HT3) receptor antagonist and dexamethasone 'with or without' the neurokinin-1 receptor antagonist, aprepitant. Aprepitant can enhance the prevention of CINV in patients who receive highly emetogenic chemotherapy (HEC), such as cisplatin (Hesketh et al, 2003; Poli-Bigelli et al, 2003; Schmoll et al, 2006) or AC (Warr et al, 2005). According to the NCCN guidelines, aprepitant use is recommended only for select patients receiving MEC, such as carboplatin or irinotecan. However, the characteristics of these 'select' patients are unclear, and no randomised trials support this strategy for non-AC MEC. The Multinational Association of Supportive Care in Cancer (MASCC) does not recommend aprepitant for non-AC MEC regimens (Roila et al, 2010). Rapoport et al (2010) reported a phase III, gender-stratified trial of aprepitant in 848 patients, showing that aprepitant significantly improved the primary end point of no vomiting as well as the secondary end point of complete response (CR) rate after MEC, including $\mathrm{AC}$ or non-AC regimens. Dexamethasone was administered only on day 1 . In the subgroup analysis of 428 patients undergoing non-AC MEC, although the primary end point of no vomiting was significantly different (aprepitant group, 83.2\%; placebo group, 71.3\%), the secondary end point of overall CR rate did not differ significantly between the groups (aprepitant group, 74.2\%; placebo group, 65.5\%). Addition of dexamethasone on days 2 and 3 may have increased the overall $\mathrm{CR}$ rate and reduced the difference in efficacy between aprepitant and placebo. This trial was not considered sufficiently compelling to recommend the standard use of aprepitant in non-AC chemotherapy. However, Waqar et al (2008) reported that among lung cancer patients, vomiting occurred in a higher proportion of women (31\%) compared with men (8\%) within $72 \mathrm{~h}$ after carboplatin administration (area under the curve (AUC), 5), suggesting that aprepitant might be effective in 'select' patients, such as women.

Corticosteroids are recommended for the prevention of acute and delayed emesis following HEC and MEC (Ioannidis et al, 2000). The recommended dose of dexamethasone on the first day of MEC is $8 \mathrm{mg}$ (Roila et al, 2010; Basch et al, 2012) or $12 \mathrm{mg}$ (Ettinger et al, 2012). On the other hand, a 20-mg dose of dexamethasone may prevent CINV more effectively in patients who receive HEC (IGAR, 1998). Although carboplatin-based MEC is less emetogenic than HEC, the optimal dose of dexamethasone in selected patients who receive carboplatin may more closely resemble to that in patients who receive cisplatin because carboplatin is a platinum agent. However, it remains unclear which patients who receive carboplatin-based MEC would benefit from an increased dose of dexamethasone equivalent to that used for HEC, given the potentially greater risk of adverse effects.

We hypothesised that women $<70$ years who did not drink alcohol were at a high risk for CINV, even after non-AC MEC. However, it is unknown whether 5-HT3 receptor antagonist and an increased dose of dexamethasone equivalent to that used for HEC adequately prevent CINV or whether additional treatment with aprepitant prevents CINV more effectively in these selected patients. We conducted a multicenter, placebo-controlled, double-blind, randomised phase II study to evaluate the effectiveness of aprepitant for preventing CINV after carboplatin- or irinotecanbased MEC in nondrinking women $<70$ years.

\section{PATIENTS AND METHODS}

Study design. This trial was conducted between January 2011 and September 2012 after the approval from each site's institutional review board. Written informed consent was obtained from all the patients who were enrolled with the use of an online registration system. The patinets were stratified according to performance status (PS; 0 or 1-2), institution, and chemotherapy regimens (carboplatin or irinotecan), then randomly assigned to the aprepitant group or placebo group according to a computer-generated, blinded allocation schedule. The investigator, study nurses, and participants remained blinded to the treatment assignments. To ensure in-house blinding, the assigned treatment and intravenous dexamethasone were dispensed by a pharmacist who was not otherwise involved in the study. Matched placebos for oral aprepitant were used to maintain double blinding. Patients completed a diary to report vomiting episodes, rescue therapy use, and daily nausea assessments from the initiation of chemotherapy infusion $(0 \mathrm{~h})$ until the morning of day $6(120 \mathrm{~h})$ after chemotherapy. This study has been registered in the University Medical Information Network Clinical Trials Registry as No. 000004998.

Patient population. Women aged 20-69 years with histologically confirmed malignancies who were naive to aprepitant and scheduled to receive carboplatin- or irinotecan-based regimens were included in this study. Patients with a history of alcohol consumption, defined as $\geqslant 1$ alcoholic drinks per week, were excluded. MEC regimens authorised for use in this study were as follows: (i) carboplatin (AUC $6 \mathrm{mg} \mathrm{min} \mathrm{ml}^{-1}$ ) plus intravenous cytotoxic antitumor drugs, such as paclitaxel and pemetrexed; (ii) carboplatin (AUC $5 \mathrm{mg} \mathrm{min} \mathrm{ml}^{-1}$ ) plus paclitaxel $\left(200 \mathrm{mg} \mathrm{m}^{-2}\right.$ );

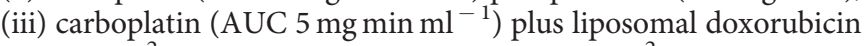
$\left(30 \mathrm{mg} \mathrm{m}^{-2}\right)$; and (iv) irinotecan $\left(\geqslant 150 \mathrm{mg} \mathrm{m}^{-2}\right)$ plus fluorouracil, bevacizumab, or cetuximab. Eligible patients had to have an Eastern Cooperative Oncology Group PS of 0-2 and an estimated life expectancy of at least 3 months and had to meet the following laboratory criteria: neutrophil count $\geqslant 1500 \mathrm{~mm}^{-3}$; platelet count $\geqslant 100000 \mathrm{~mm}^{-3}$; aspartate aminotransferase and alanine aminotransferase $\leqslant 2.5$ times the upper limit of the normal range at the facility; total bilirubin $\leq 1.5$ times the upper limit of the normal range at the facility; and creatinine $\leqslant 1.5$ times the upper limit of the normal range at the facility. We also excluded patients at risk of vomiting for other reasons (symptomatic brain metastasis, meningeal infiltration, epilepsy, active peptic ulcers, gastrointestinal obstruction, concomitant abdominal, or pelvic radiotherapy), pregnant, nursing, or possibly pregnant women.

Treatment. The doses of each drug according to the study group are shown in Table 1 . On day 1, administration of the first MEC

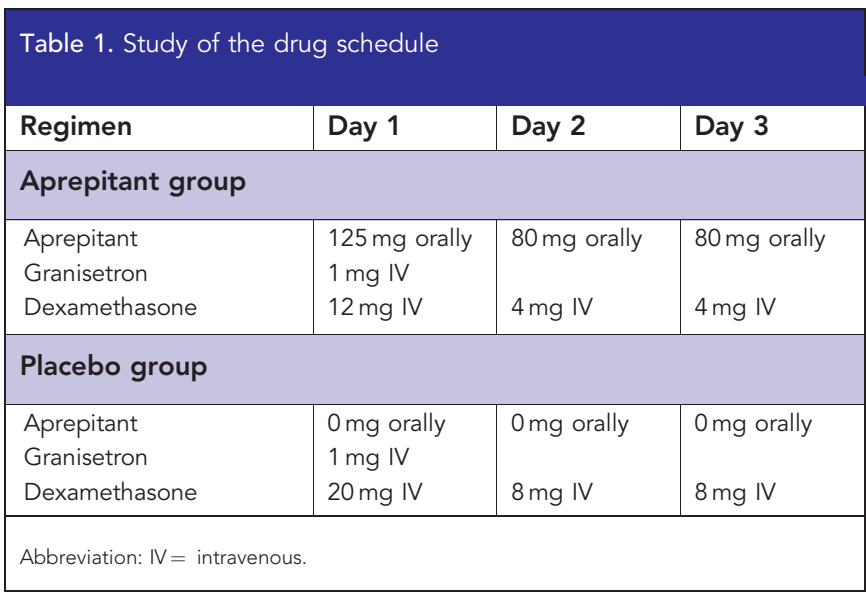


agent was started $1 \mathrm{~h}$ after oral administration of the aprepitant or placebo and $30 \mathrm{~min}$ after intravenous granisetron and dexamethasone. On days 2 and 3, oral aprepitant or placebo and intravenous dexamethasone were administered in the morning. Concomitant use of other antiemetics was prohibited from $48 \mathrm{~h}$ before day 1 to the morning of day 6 , with the exclusion of rescue therapy for CINV.

Assessments. Patients completed a daily assessment for 5 days of the first chemotherapy cycle from the start of MEC on day 1 to the morning of day 6 to record vomiting or retching episodes, rescue therapy, and nausea ratings. For nausea, patients rated the most severe episode during the previous 24 -h period according to a fourpoint scale (none, mild, moderate, severe). All adverse events were categorised according to the National Cancer Institute Common Toxicity Criteria for Adverse Events, version 4.0. Pretreatment plasma estradiol and progesterone levels were measured as exploratory predictors of CINV within 1 week before initiating MEC.

Statistical analysis. The primary end point was the rate of CR, defined as no vomiting or retching episodes with no rescue medication for $120 \mathrm{~h}$ from the start of the first cycle of MEC. The criteria were applied to evaluate CR in the acute (0-24h), delayed $(24-120 \mathrm{~h})$, and overall $(0-120 \mathrm{~h})$ phases. The following key secondary end points were also analysed: (i) no emesis; (ii) no rescue therapy; (iii) no significant nausea (nausea score: none and mild); (iv) no nausea (nausea score: 0); and (v) total control (no emesis, no rescue therapy, and no nausea (nausea score: 0 )).

This study was a randomised phase II trial comparing the aprepitant group with the placebo group. In the phase III trial of aprepitant in patients who received non-AC MEC (Rapoport et al, 2010 ), the CR rate in the plaebo group was $65.5 \%$. This rate was anticipated to be lower in nondrinking women $<70$ years receiving only carboplatin- or irinotecan-based regimens; however, the difference was expected to be offset by the additional doses of dexamethasone on days 2 and 3. Therefore, we estimated the CR rate in the placebo group to be $65 \%$ in our study. Treatment with aprepitant was expected to increase the CR rate by $20 \%$ on the basis of the results of phase III trials of aprepitant in patients who received HEC (Hesketh et al, 2003; Poli-Bigelli et al, 2003), given that CINV induced by MEC in these selected patients would be similar to CINV by HEC. Assuming a one-sided significance level of $10 \%$ for testing the primary hypothesis, the sample size was calculated based on the hypothesis that $\mathrm{CR}$ rate of the placebo group, estimated at $65 \%$, would improve by $20 \%$ in the aprepitant group. Given a total sample size of 90 patients (45 per group), the statistical power was estimated to be $82 \%$. Assuming that approximately $5 \%$ of the subjects would be withdrawn or drop out, the target sample size was set at 94 in total and 47 per group. Exploratory subgroup analysis of predictive factors of $\mathrm{CR}$ in the overall phase was performed by logistic regression analysis. Variables with $P$ values of $\leqslant 0.10$ on univariate analysis and clinically important variables (age, PS, allocation) were included in the multivariate analysis. All statistical analyses were performed using the IBM SPSS Statistics 20 (IBM, Armonk, NY, USA).

\section{RESULTS}

Patients. A total of 94 patients were enrolled in this study and randomly assigned to one of the two treatment arms (Figure 1). Of these, 91 patients were included in the full analysis set. Both treatment groups had similar baseline demographics (Table 2). Most patinets (98\%) underwent carboplatin-based chemotherapy. Common malignancies were ovarian/peritoneal cancer (55\%) and uterine endometrial cancer (38\%). Thirty-nine (43\%) patients were 60-69 years old.

Efficacy. The percentages of patients with CR in the overall, acute, and delayed phases for each treatment are shown in Figure 2. The CR rate in the overall phase was superior but not significantly higher in the aprepitant group than in the placebo group (aprepitant group, 62.2\% (28 out of 45 ); placebo group, $52.1 \%$ (24 out of 46$) ; P=0.33$ ). The difference was 10.1 percentage points ( $90 \%$ confidence interval, $-7 \%$ to $27 \%$ ). The acute phase efficacies were similarly high in both the groups (aprepitant group, $97.8 \%$ (44 out of 45); placebo group, $95.7 \%$ (24 out of 46)) and the delayed phase efficacy was the same as the overall efficacy. For each predefined, secondary end point and treatment, the overall phase efficacies are shown in Table 3. The median day of the first episode of vomiting or of rescue use was day 4 in both the groups. Eighteen (20\%) patients used rescue therapy in the absence of clinically significant nausea or vomiting. The CR rates in the 14 patients with

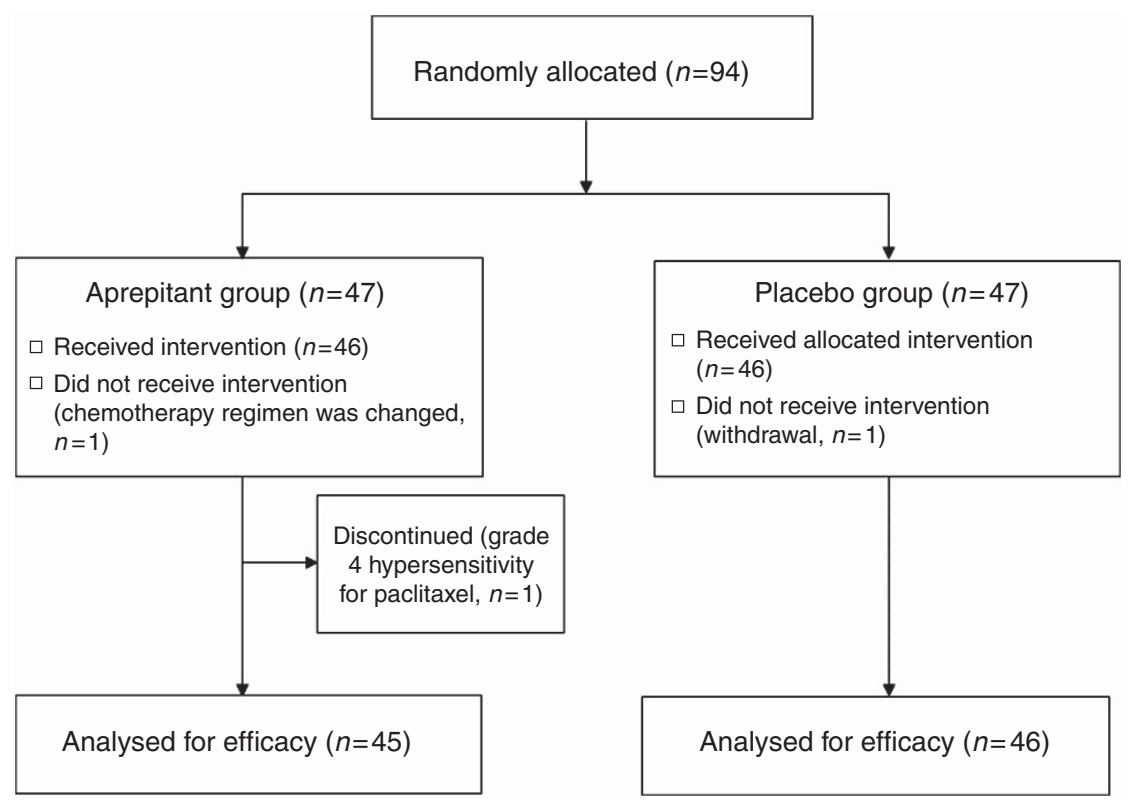

Figure 1. Study flow chart. 


\begin{tabular}{|c|c|c|}
\hline Characteristics & $\begin{array}{l}\text { Aprepitant } \\
\text { group }(n=45)\end{array}$ & $\begin{array}{c}\text { Placebo } \\
\text { group }(n=46)\end{array}$ \\
\hline Median age, years & $58(36-67)$ & 59 (33-69) \\
\hline$\geqslant 60$ years & 18 & 21 \\
\hline Performance status $0 / 1 / 2$ & $28 / 16 / 1$ & $31 / 13 / 2$ \\
\hline History of motion sickness & 13 & 11 \\
\hline History of morning sickness & 29 & 27 \\
\hline History of platinum chemotherapy & 7 & 5 \\
\hline $\begin{array}{l}\text { History of chemotherapy } \\
\text { except platinum }\end{array}$ & 2 & 0 \\
\hline \multicolumn{3}{|l|}{ Type of malignancy } \\
\hline Ovarian cancer (early/advanced ${ }^{\mathrm{a}}$ ) & $28(6 / 22)$ & $26(9 / 17)$ \\
\hline Endometrial cancer & 12 & 16 \\
\hline Other ${ }^{\mathbf{b}}$ & 5 & 4 \\
\hline $\begin{array}{l}\text { Ascites or peritoneal } \\
\text { dissemination }\end{array}$ & 27 & 20 \\
\hline \multicolumn{3}{|l|}{ Chemotherapy regimen } \\
\hline CBDCA (AUC 6)+PTX (175d) & 22 & 28 \\
\hline CBDCA (AUC 6) + PTX (80d) & 19 & 16 \\
\hline CBDCA (AUC 5) + PTX $\left(200^{d}\right)$ & 1 & 0 \\
\hline $\begin{array}{l}\text { CBDCA (AUC } 5)+ \\
\text { pemextrexed }+ \text { bevacizumab }\end{array}$ & 0 & 1 \\
\hline CBDCA (AUC 5) + PLD & 2 & 0 \\
\hline FOLFIRI ${ }^{c}$ & 1 & 1 \\
\hline \multicolumn{3}{|c|}{ 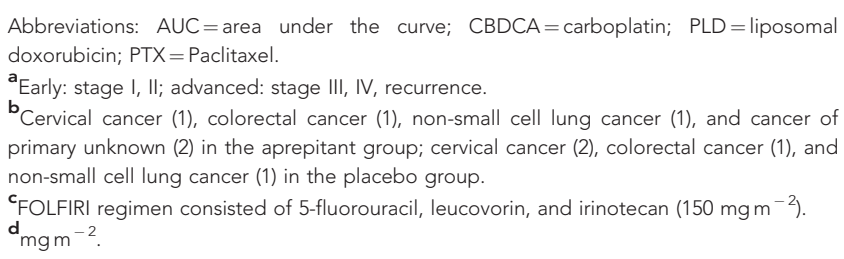 } \\
\hline
\end{tabular}

a previous history of chemotherapy were similar in the treatment groups (aprepitant group, 78\% (7 out of 9); placebo group, $80 \%$ (4 out of 5)).

The results of univariate logistic regression analysis of factors related to CR are shown in Table 4. Pretreatment plasma levels of estradiol or progesterone did not significantly correlate with the overall CR. Variables tested in the multivariate analysis were age, PS, history of chemotherapy, treatment allocation (aprepitant or placebo), ascites/peritoneal dissemination, and advanced (stage III/IV, recurrent) ovarian/primary peritoneal cancer. After controlling for these factors, the only independent predictor of a lower CR was advanced ovarian/primary peritoneal cancer (OR, 0.26 (0.10-0.72); $P=0.010$; Table 5). Among the 39 patients with advanced ovarian/ primary peritoneal cancer, the overall CR was $45 \%$ (10 out of 22$)$ in the aprepitant group and 29\% (5 out of 17) in the placebo group, respectively.

Tolerability. Safety was evaluated in all the 92 subjects who were assigned to treatment, including the patient who discontinued chemotherapy due to a hypersensitivity reaction. Generally, the adverse event profile did not markedly differ between the groups, although myalgia/arthralgia was more common in the placebo group (Table 5). One patient in the placebo group experienced grade 2 upper gastrointestinal bleeding on day 2, which might have been caused by dexamethasone; however, most events were mild and self-limiting. No grade 3-4 adverse events were observed except for a grade 4 hypersensitivity reaction to paclitaxel $(n=1)$ in the aprepitant group. A slight decrease in the incidence of

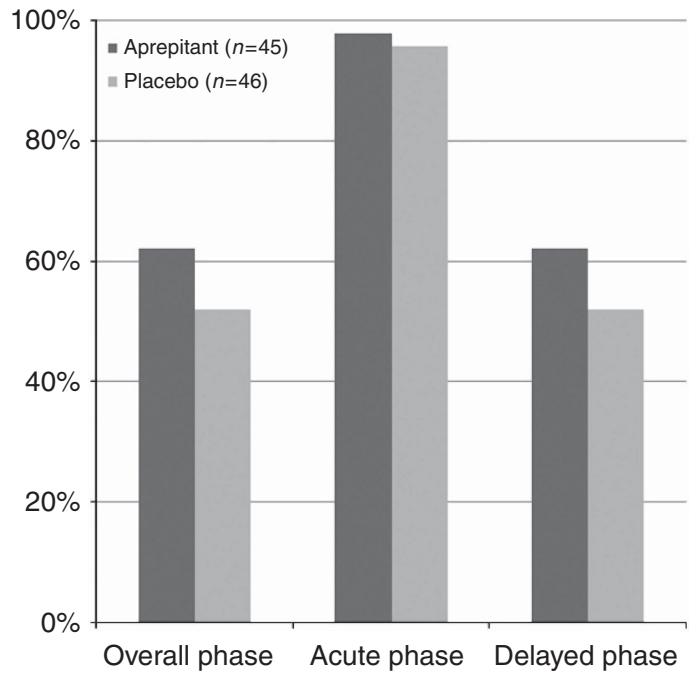

Figure 2. Complete response by phase. The bar graph shows the percentages of patients achieving a complete response (CR) in the overall, acute, and delayed phases. CR was defined as no vomiting and no use of rescue medication. Black and gray bars represent the aprepitant and placebo regimens, respectively. The overall, acute, and delayed phases were 0-120 h, 0-24 h, and 25-120 h, respectively, after initiation of chemotherapy.

anorexia was noted in patients receiving aprepitant (74\%) compared with patients receiving the placebo (85\%).

\section{DISCUSSION}

To our knowledge, this study is the first randomised trial to evaluate aprepitant in 'select' patients, that is, nondrinking female patients $<70$ years who mainly received carboplatin-based MEC. Nearly half $(47.9 \%)$ of the patients experienced vomiting or used rescue medication after MEC despite treatment with granisetron and an increased dose of dexamethasone. This was much lower than our expected CR rate of $65 \%$ and partly due to the low CR rate of $29 \%$ in 17 patients with advanced ovarian cancer. Addition of aprepitant seemed to be effective even with an increased dose of dexamethasone; however, improvement is required in the delayed phase CR rate of $62.2 \%$. The addition of aprepitant resulted in a $10.1 \%$ non-significant improvement in the overall CR rate, which was also lower than our initial expectation of $20 \%$. We had thus overestimated the benefit of aprepitant for the prevention of nonAC MEC. This non-significant result might be attributed to the small sample size in our trial, and a $10.1 \%$ improvement might be statistically significant in a larger study group. In a study of 857 patients with breast cancer who received AC, however, the efficacy of aprepitant was only an $8.3 \%$ improvement of $\mathrm{CR}$ rate (aprepitant group, 50.8\%; placebo group, 42.5\%; Warr et al, 2005), and all guidelines recommend the standard use of aprepitant in patients who receive AC chemotherapy. We still believe that a $10.1 \%$ improvement is promising and that further confirmatory phase III trials of aprepitant in this population are warranted. The overall CR rates in the 14 patients with a previous history of chemotherapy were similiar between the groups, suggesting previous chemotherapy did not influence the overall results of our study.

Among the 91 subjects included in the full analysis set, the proportion of patients without significant nausea was $80 \%$, which was higher than the $59 \%$ of patients who did not use rescue therapy (Table 3). Indeed, $20 \%$ of the patients used rescue therapy in the absence of subjective significant nausea or vomiting. This finding 


\begin{tabular}{|c|c|c|c|c|}
\hline End points & $\begin{array}{c}\text { Aprepitant } \\
(n=45)\end{array}$ & $\begin{array}{c}\text { Placebo } \\
(n=46)\end{array}$ & $\boldsymbol{P}$ & $\begin{array}{r}\text { Diffrence } \\
(90 \% \mathrm{Cl})\end{array}$ \\
\hline Complete response & $28(62 \%)$ & $24(52 \%)$ & 0.33 & $10 \%(-7 \%, 27 \%)$ \\
\hline No vomiting & $38(83 \%)$ & $36(78 \%)$ & 0.45 & $6 \%(-7 \%, 20 \%)$ \\
\hline No significant nausea ${ }^{a}$ & 38 (83\%) & $35(76 \%)$ & 0.32 & $8 \%(-5 \%, 22 \%)$ \\
\hline No rescue therapy & $30(67 \%)$ & $24(52 \%)$ & 0.16 & $14 \%(-2 \%, 31 \%)$ \\
\hline No nausea & $24(53 \%)$ & 18 (39\%) & 0.17 & $14 \%(-3 \%, 31 \%)$ \\
\hline Total control ${ }^{\mathbf{b}}$ & $21(47 \%)$ & 17 (37\%) & 0.35 & $10 \%(-7 \%, 27 \%)$ \\
\hline \multicolumn{5}{|c|}{$\begin{array}{l}\text { Abbreviation: } \mathrm{Cl}=\text { confidence interval. } \\
\mathrm{a}_{\text {No significant nausea; nausea score, none and mild. }} \\
\mathbf{b}_{\text {Total control: no emesis, no rescue therapy, and no nausea; nausea score, } 0 \text { ). }}\end{array}$} \\
\hline
\end{tabular}

suggests that one of the reasons for rescue use may be anxiety, which is the major cause of anticipatory nausea in cancer chemotherapy(Nerenz et al, 1986). Prophylactic benzodiazepines such as lorazepam or alprazolam may improve the delayed phase CR for such patients.

The use of palonosetron instead of granisetron might improve delayed CINV in this setting because the MASCC (Roila et al, 2010) and ASCO guidelines (Basch et al, 2012) recommend palonosetron as the preferred 5-HT3 receptor antagonist for non-AC MEC regimens. However, no clinically relevant differences between palonosetron and other 5-HT3 receptor antagonists have been demonstrated by randomised phase III trials for non-AC MEC regimens. Moreover, a recent study from the Rochester Cancer Center, New York demonstrated that delayed nausea was significantly improved by additionally giving dexamethasone on days 2 and 3; however, no difference was evident between palonosetron and granisetron after HEC or MEC (Roscoe et al, 2012). In patients who receive aprepitant, the difference between palonosetron and granisetron would be expected to be small. Other methods with the potential to improve delayed CINV are increased doses of dexamethasone on days 2 and 3, addition of dexamethasone, aprepitant, or both on days 4 and 5 , addition of prochloperazine or an 5-HT3 receptor antagonist on days 2-5, or addition of olanzapine on days 1-4 (Navari et al, 2011).

In the Rapoport study (Rapoport et al, 2010) or the phase III trial of aprepitant for HEC (Poli-Bigelli et al, 2003), the differences in the rates of $\mathrm{CR}$ and no vomiting between the aprepitant group and placebo group were $6 \%$ and $12 \%$ or $19 \%$ and $22 \%$, respectively. In our study, however, the difference in the no vomiting rate was $6 \%$, which was smaller than the $10 \%$ difference in the $\mathrm{CR}$ rate (Table 3). One reason for the small difference in the rate of no vomiting is the small sample size in our trial. The $90 \%$ confidence interval of no vomiting varied from $7 \%$ to $20 \%$. Another reason is the influence of the 12 patients who had previously received platinum-based chemotherapy. The rates of no vomiting were $86 \%$ ( 6 out of 7) and 100\% (5 out of 5) in the aprepitant group and placebo group, respectively. If these patients are excluded, the rates of no vomiting were $84 \%$ ( 32 out of 38 ) in the aprepitant group and $76 \%$ (31 out of 41 ) in the placebo group, respectively, and the difference in the rate of no vomiting slightly increased up to $8 \%$.

Some reports have demonstrated that estradiol or progesterone has a stimulatory effect on the neurokinin-1 receptor (Kerdelhue et al, 1997; Villablanca and Hanley, 1997; Kerdelhue et al, 2000) and both are potential mediators of morning sickness during pregnancy (Walsh et al, 1996; Lagiou et al, 2003). We explored whether pretreatment plasma levels of estradiol and progesterone influence CINV in younger female patients; however, neither level had a significant effect on CINV in our study. This might be partly because $>40 \%$ of our patients were $\geqslant 60$ years,
Table 4. Logistic regression analysis of predictors of $\mathrm{CR}$ in the overall

phase

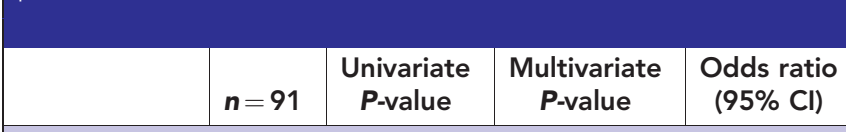

Age, years

\begin{tabular}{|l|l|l|l|c|}
\hline $60-69$ & 39 & 0.90 & 1.00 & 1.00 \\
$30-59$ & 52 & & & $(0.39-2.55)$ \\
\hline
\end{tabular}

Performance status

\begin{tabular}{|l|l|l|l|c|}
\hline 0 & 60 & 0.06 & 0.53 & 0.72 \\
$1-2$ & 31 & & & $(0.26-2.02)$ \\
\hline
\end{tabular}

History of motion sickness

\begin{tabular}{|l|l|l|l|l|}
\hline $\begin{array}{l}\text { No } \\
\text { Yes }\end{array}$ & 67 & 0.40 & & \\
\hline
\end{tabular}

History of morning sickness

\begin{tabular}{|c|c|c|c|c|}
\hline $\begin{array}{l}\text { No } \\
\text { Yes }\end{array}$ & $\begin{array}{l}35 \\
56\end{array}$ & 1.0 & & \\
\hline \multicolumn{5}{|c|}{ Previous chemotherapy } \\
\hline $\begin{array}{l}\text { No } \\
\text { Yes }\end{array}$ & $\begin{array}{l}77 \\
14\end{array}$ & 0.09 & 0.16 & $\begin{array}{c}2.80 \\
(0.67-11.8)\end{array}$ \\
\hline
\end{tabular}

Advanced ovarian/peritoneal cancer

\begin{tabular}{|l|c|c|c|c|}
\hline No & 52 & 0.002 & 0.010 & 0.26 \\
Yes & 39 & & & $(0.10-0.72)$ \\
\hline
\end{tabular}

Pretreatment estradiol

\begin{tabular}{|l|l|l|}
\hline$<10 \mathrm{pg} \mathrm{ml}^{-1}$ & 56 & 0.22 \\
$\geqslant 10 \mathrm{pg} \mathrm{ml}^{-1}$ & 31 & \\
\hline
\end{tabular}

Pretreatment progesterone

\begin{tabular}{l|l|l|l|c|}
\hline $\begin{array}{l}<0.3 \mathrm{ng} \mathrm{ml}^{-1} \\
\geqslant 0.3 \mathrm{ngl}^{-1}\end{array}$ & $\begin{array}{l}66 \\
21\end{array}$ & 0.94 & & \\
\hline Allocation & & \\
\hline $\begin{array}{l}\text { Placebo } \\
\text { Aprepitant }\end{array}$ & 46 & 0.33 & 0.23 & $\begin{array}{c}1.77 \\
(0.69-4.50)\end{array}$ \\
\hline
\end{tabular}

Abbreviations: $\mathrm{Cl}=$ confidence interval; $\mathrm{CR}=$ complete response. Variables tested for inclusion in the multivariate Cox regression model were age 30-59 years, PS of 1-2, history of chemotherapy, allocation (aprepitant or placebo), ascites or peritoneal dissemination, and advanced (Stage III/IV, recurrent) ovarian/primary peritoneal cancer.

Table 5. Patients with specific clinical adverse events of incidence $\geqslant 5 \%$ in at least one treatment group

\begin{tabular}{|l|c|c|c|c|}
\cline { 2 - 5 } \multicolumn{1}{c|}{} & \multicolumn{2}{c|}{ Aprepitant (n=46) } & \multicolumn{2}{c|}{ Placebo (n=46) } \\
\hline Adverse events & Grade 1 & Grade 2 & Grade 1 & Grade 2 \\
\hline Anorexia & 21 & 13 & 25 & 14 \\
\hline Myalgia/arthralgia & 2 & 1 & 7 & 2 \\
\hline Fatigue & 4 & 3 & 4 & 2 \\
\hline Constipation & 2 & 3 & 1 & 1 \\
\hline Diarrhea & 3 & 1 & 2 & 1 \\
\hline
\end{tabular}

No grade 3-4 adverse events were observed except grade 4 hypersensitivity $(n=1)$ in the aprepitant group. 
and nearly half had undergone bilateral oophorectomy. Exploratory analysis showed that only advanced ovarian/peritoneal cancer was a significantly poor predictor of CINV, although the results of analysis might have been different or other variables might also have been found to be significant predictors of CR if the sample size had been larger. Among the 39 patients with advanced ovarian/peritoneal cancer, $86 \%$ (19 out of 22) in the aprepitant group and $88 \%$ (15 out of 17) in the placebo group had ascites or peritoneal dissemination. Therefore, the presence of ascites or peritoneal dissemination might have influenced CINV in patients with advanced ovarian/peritoneal cancer. Study groups including advanced ovarian/peritoneal cancer patients should be stratified according to cancer type in future antiemetic trials. Furthermore, aprepitant was associated with a $16 \%$ improvement in the overall CR in patients with advanced ovarian/peritoneal cancer (45\% (10 out of 22 ) vs $29 \%$ (5 out of 17$)$ ); therefore, aprepitant might be more effective than placebo even in such patients, and additional studies are required to optimise treatment for this important subset of patients.

In conclusion, aprepitant in combination with granisetron and an increased dose of dexamethasone equivalent to that used for HEC was well tolerated and seemed more effective than placebo for the prevention of CINV in nondrinking women $<70$ years who received MEC. However, delayed-phase CINV remains a significant problem. Further confirmatory trials of aprepitant in this population are warranted.

\section{ACKNOWLEDGEMENTS}

We thank all participating patients, centers, and the study office of the Hanshin Cancer Study Group (Mitsuho Edagawa (Kobe City Medical Center General Hospital, Kobe)). We thank Dr. Miyako Satouchi (Department of Thoracic Oncology, Hyogo Cancer Center, Akashi), Takuma Onoe, Yoshitaka Kikukawa, Naoto Takase (Medical Oncology, Hyogo Cancer Center, Akashi) and Dr. Takako Okuyama (Department of Clinical Oncology, Osaka Medical Center for Cancer and Cardiovascular Diseases, Osaka) who participated as investigators in this trial. We also thank Dr. Naotoshi Sugimoto (Department of Clinical Oncology, Osaka Medical Center for Cancer and Cardiovascular Diseases, Osaka) for helpful discussions and Junko Tsujimoto and Wakako Murata (Department of Pharmacy, Hyogo Cancer Center, Akashi) for on-line registration and dispensing. The study protocol was funded by the Hanshin Oncology Study Group.

\section{CONFLICT OF INTEREST}

HM reported having accepted an unrestricted research grant and received honoraria from Ono Pharmaceutical Co., Ltd. The other authors declareno conflict of interest.

\section{REFERENCES}

Basch E, Prestrud AA, Hesketh PJ, Kris MG, Feyer PC, Somerfield MR, Chesney M, Clark-Snow RA, Flaherty AM, Freundlich B, Morrow G, Rao KV, Schwartz RN, Lyman GH (2012) Antiemetics: American Society of Clinical Oncology clinical practice guideline update. J Clin Oncol 29: 4189-4198.

Ettinger DS, Armstrong DK, Barbour S, Berger MJ, Bierman PJ, Bradbury B, Ellis G, Kirkegaard S, Kloth DD, Kris MG, Lim D, Michaud LB, Nabati L, Noonan K, Rugo HS, Siler D, Sorscher SM, Stelts S, Stucky-Marshall L, Todaro B, Urba SG (2012) Antiemesis. J Natl Compr Canc Netw 10: 456-485.

Hesketh PJ (2008) Chemotherapy-induced nausea and vomiting. N Engl J Med 358: $2482-2494$.
Hesketh PJ, Aapro M, Street JC, Carides AD (2010) Evaluation of risk factors predictive of nausea and vomiting with current standard-of-care antiemetic treatment: analysis of two phase III trials of aprepitant in patients receiving cisplatin-based chemotherapy. Support Care Cancer 18: 1171-1177.

Hesketh PJ, Grunberg SM, Gralla RJ, Warr DG, Roila F, De Wit R, Chawla SP, Carides AD, Ianus J, Elmer ME, Evans JK, Beck K, Reines S, Horgan KJ (2003) The oral neurokinin-1 antagonist aprepitant for the prevention of chemotherapy-induced nausea and vomiting: a multinational, randomized, double-blind, placebo-controlled trial in patients receiving high-dose cisplatin-the Aprepitant Protocol 052 Study Group. J Clin Oncol 21: 4112-4119.

IGAR (1998) Double-blind, dose-finding study of four intravenous doses of dexamethasone in the prevention of cisplatin-induced acute emesis. J Clin Oncol 16: 2937-2942.

Ioannidis JP, Hesketh PJ, Lau J (2000) Contribution of dexamethasone to control of chemotherapy-induced nausea and vomiting: a meta-analysis of randomized evidence. J Clin Oncol 18: 3409-3422.

Kerdelhue B, Gordon K, Williams R, Lenoir V, Fardin V, Chevalier P, Garret C, Duval P, Kolm P, Hodgen G, Jones H, Jones GS (1997) Stimulatory effect of a specific substance $P$ antagonist (RPR 100893) of the human NK1 receptor on the estradiol-induced LH and FSH surges in the ovariectomized cynomolgus monkey. J Neurosci Res 50: 94-103.

Kerdelhue B, Williams RF, Lenoir V, Fardin V, Kolm P, Hodgen GD, Jones GS, Scholler R, Jones Jr HW (2000) Variations in plasma levels of substance $\mathrm{P}$ and effects of a specific substance $\mathrm{P}$ antagonist of the $\mathrm{NK}(1)$ receptor on preovulatory LH and FSH surges and progesterone secretion in the cycling cynomolgus monkey. Neuroendocrinology 71: $228-236$.

Kris MG, Hesketh PJ, Somerfield MR, Feyer P, Clark-Snow R, Koeller JM, Morrow GR, Chinnery LW, Chesney MJ, Gralla RJ, Grunberg SM (2006) American Society of Clinical Oncology guideline for antiemetics in oncology: update 2006. J Clin Oncol 24: 2932-2947.

Lagiou P, Tamimi R, Mucci LA, Trichopoulos D, Adami HO, Hsieh CC (2003) Nausea and vomiting in pregnancy in relation to prolactin, estrogens, and progesterone: a prospective study. Obstet Gynecol 101: 639-644.

Navari RM, Gray SE, Kerr AC (2011) Olanzapine versus aprepitant for the prevention of chemotherapy-induced nausea and vomiting: a randomized phase III trial. J Support Oncol 9: 188-195.

Nerenz DR, Leventhal H, Easterling DV, Love RR (1986) Anxiety and drug taste as predictors of anticipatory nausea in cancer chemotherapy. J Clin Oncol 4: 224-233.

Oo TH, Hesketh PJ (2005) Drug insight: new antiemetics in the management of chemotherapy-induced nausea and vomiting. Nat Clin Pract Oncol 2: 196-201.

Osoba D, Zee B, Pater J, Warr D, Latreille J, Kaizer L (1997) Determinants of postchemotherapy nausea and vomiting in patients with cancer. Quality of Life and Symptom Control Committees of the National Cancer Institute of Canada Clinical Trials Group. J Clin Oncol 15: 116-123.

Poli-Bigelli S, Rodrigues-Pereira J, Carides AD, Julie Ma G, Eldridge K, Hipple A, Evans JK, Horgan KJ, Lawson F (2003) Addition of the neurokinin 1 receptor antagonist aprepitant to standard antiemetic therapy improves control of chemotherapy-induced nausea and vomiting. Results from a randomized, double-blind, placebo-controlled trial in Latin America. Cancer 97: 3090-3098.

Pollera CF, Giannarelli D (1989) Prognostic factors influencing cisplatininduced emesis. Definition and validation of a predictive logistic model. Cancer 64: 1117-1122.

Rapoport BL, Jordan K, Boice JA, Taylor A, Brown C, Hardwick JS, Carides A, Webb T, Schmoll HJ (2010) Aprepitant for the prevention of chemotherapy-induced nausea and vomiting associated with a broad range of moderately emetogenic chemotherapies and tumor types: a randomized, double-blind study. Support Care Cancer 18 : 423-431.

Roila F, Fatigoni S (2006) New antiemetic drugs. Ann Oncol 17(Suppl 2): ii96-100. Roila F, Herrstedt J, Aapro M, Gralla RJ, Einhorn LH, Ballatori E, Bria E, Clark-Snow RA, Espersen BT, Feyer P, Grunberg SM, Hesketh PJ, Jordan K, Kris MG, Maranzano E, Molassiotis A, Morrow G, Olver I, Rapoport BL, Rittenberg C, Saito M, Tonato M, Warr D (2010) Guideline update for MASCC and ESMO in the prevention of chemotherapy- and radiotherapy-induced nausea and vomiting: results of the Perugia consensus conference. Ann Oncol 21(Suppl 5): v232-v243. 
Roscoe JA, Heckler CE, Morrow GR, Mohile SG, Dakhil SR, Wade JL, Kuebler JP (2012) Prevention of delayed nausea: a university of Rochester cancer center community clinical oncology program study of patients receiving chemotherapy. J Clin Oncol 30: 3389-3395.

Schmoll HJ, Aapro MS, Poli-Bigelli S, Kim HK, Park K, Jordan K, von Pawel J, Giezek H, Ahmed T, Chan CY (2006) Comparison of an aprepitant regimen with a multiple-day ondansetron regimen, both with dexamethasone, for antiemetic efficacy in high-dose cisplatin treatment. Ann Oncol 17: 1000-1006.

Schwartzberg LS (2007) Chemotherapy-induced nausea and vomiting: clinician and patient perspectives. J Support Oncol 5: 5-12.

Villablanca AC, Hanley MR (1997) 17beta-estradiol stimulates substance P receptor gene expression. Mol Cell Endocrinol 135 : 109-117.

Walsh JW, Hasler WL, Nugent CE, Owyang C (1996) Progesterone and estrogen are potential mediators of gastric slow-wave dysrhythmias in nausea of pregnancy. Am J Physiol 270: G506-G514.
Waqar MA, Chitneni P, Williams K, Goodgame BW, Gao F, Govindan R, Baggstrom MQ (2008) A prospective study on the incidence of delayed nausea and vomiting following administration of carboplatin containing regimens for treatment of cancer without prophylactic aprepitant. J Clin Oncol (Meeting Abstracts) 26: 20626.

Warr DG, Hesketh PJ, Gralla RJ, Muss HB, Herrstedt J, Eisenberg PD, Raftopoulos H, Grunberg SM, Gabriel M, Rodgers A, Bohidar N, Klinger G, Hustad CM, Horgan KJ, Skobieranda F (2005) Efficacy and tolerability of aprepitant for the prevention of chemotherapy-induced nausea and vomiting in patients with breast cancer after moderately emetogenic chemotherapy. J Clin Oncol 23: 2822-2830.

This work is published under the standard license to publish agreement. After 12 months the work will become freely available and the license terms will switch to a Creative Commons AttributionNonCommercial-Share Alike 3.0 Unported License. 